\title{
ON THE SPHERICAL DERIVATIVE OF A MEROMORPHIC FUNCTION WITH A NEVANLINNA DEFICIENT VALUE
}

\section{SAKARI TOPPILA}

\section{Introduction and results}

I thank Professor D. Shea for suggesting this subject to me.

Let $f$ be a meromorphic function in the complex plane. We write

$$
\varrho(f(z))=\frac{\left|f^{\prime}(z)\right|}{1+|f(z)|^{2}}
$$

and

$$
\mu(r, f)=\sup \{\varrho(f(z)):|z|=r\} .
$$

We shall use the usual notations of the Nevanlinna theory. The following result is proved in [11].

Theorem A. Let $f$ be a transcendental meromorphic function in the plane such that $\delta(\infty, f)>0$. Then

$$
\limsup _{\substack{z \rightarrow \infty \\ z \in E(f)}} \frac{|z| \varrho(f(z))}{T(|z|, f)} \geqq A_{0}(1+t) \delta(\infty, f),
$$

where $A_{0}>0$ is an absolute constant, $t$ is the order of $f$ and

$$
E(f)=\{z:|f(z)|=1\}
$$

In the other direction, we shall prove the following result.

Theorem 1. For any $d, 0<d \leqq 1$, and $t, 0<t<\infty$, there exists a meromorphic function $f$ of order $t$ such that $\delta(\infty, f)=d$ and that

$$
\limsup _{r \rightarrow \infty} \frac{r \mu(r, f)}{T(r, f)} \leqq 60(1+t) \delta(\infty, f) .
$$




\section{Some lemmas}

Lemma 1. Let $k$ be a positive integer,

and

$$
\begin{gathered}
g(z)=\frac{1}{1-z^{8 k}}, \\
g_{p}(z)=g\left(2^{-p / k} z\right) \text { for } p=1, \ldots, k,
\end{gathered}
$$

Then $n\left(r, \infty, f_{k}\right)=8 k^{2}$ for $r \geqq 2$,

$$
f_{k}(z)=\sum_{p=1}^{k}(-1)^{p} g_{p}(z)
$$

$$
\varrho\left(f_{k}(z)\right)<72 k
$$

for all $z$ in the finite complex plane $C$, and if $|z| \geqq 4$, then

$$
\left|f_{k}(z)\right| \leqq|2 / z|^{6 k} \text {. }
$$

Proof. It follows immediately from the definition of $f_{k}$ that the number of the poles of $f_{k}$ is $8 k^{2}$ and that all the poles lie on $|z| \leqq 2$.

Let $|z| \geqq 4$. We get

which proves (2.2).

$$
\begin{aligned}
\left|f_{k}(z)\right| & \leqq \sum_{p=1}^{k}\left(\left|2^{-p / k} z\right|^{8 k}-1\right)^{-1} \leqq k\left(|z / 2|^{8 k}-1\right)^{-1} \\
& \leqq 2 k|2 / z|^{6 k}(2 / 4)^{2 k} \leqq|2 / z|^{6 k},
\end{aligned}
$$

Let $s, 1 \leqq s \leqq k$, be an integer. If

and $p \leqq s$, we get

$$
|z| \geqq 2^{(s+1 / 2) / k}
$$

$$
\left|g_{p}(z)\right| \leqq\left(\left(2^{(s+1 / 2) / k} / 2^{p / k}\right)^{8 k}-1\right)^{-1}=\left(16\left(2^{8}\right)^{s-p}-1\right)^{-1} \leqq\left(15\left(2^{8}\right)^{s-p}\right)^{-1} .
$$

If

and $p \geqq s$, we get

$$
|z| \leqq 2^{(s-1 / 2) / k}
$$

$$
\left|g_{p}(z)-1\right|=\left|\left(z^{-1} 2^{p / k}\right)^{8 k}-1\right|^{-1} \leqq\left(\left(2^{8}\right)^{p-s+1 / 2}-1\right)^{-1} \leqq\left(15\left(2^{8}\right)^{p-s}\right)^{-1} .
$$

Since

$$
g_{p}^{\prime}(z)=8 k z^{-1} g_{p}(z)\left(g_{p}(z)-1\right),
$$

we get in both cases the estimate

$$
\left|g_{p}^{\prime}(z)\right| \leqq 8 k|z|^{-1}(1+1 / 15)\left(15\left(2^{8}\right)^{|s-p|}\right)^{-1}=\frac{128 k}{225|z|}\left(2^{8}\right)^{-|s-p|} .
$$

From (2.6) we deduce that if $|z|=2^{1 /(2 k)}$ or $|z| \geqq 2^{(k+1 / 2) / k}$, then

$$
\left|f_{k}^{\prime}(z)\right| \leqq \frac{128 k}{225} \sum_{t=0}^{\infty}\left(2^{8}\right)^{-t} \leqq k,
$$


and using the maximum principle and the fact that

we conclude that

$$
\varrho\left(f_{k}(z)\right) \leqq\left|f_{k}^{\prime}(z)\right|,
$$

$$
\varrho\left(f_{k}(z)\right) \leqq k
$$

if $|z| \leqq 2^{1 /(2 k)}$ or $|z| \geqq 2^{(k+1 / 2) / k}$.

Let $s, 1 \leqq s \leqq k$, be fixed and let

$$
2^{(s-1 / 2) / k} \leqq|z| \leqq 2^{(s+1 / 2) / k} .
$$

We write $f_{k}(z)=g_{s}(z)+h(z)$. It follows from (2.3) and (2.4) that

$$
\begin{gathered}
|h(z)| \leqq \sum_{p=1}^{s-1}\left|g_{p}(z)\right|+\left|\sum_{p=s+1}^{k}(-1)^{p}\right| \\
+\sum_{p=s+1}^{k}\left|1-g_{p}(z)\right| \leqq 1+(2 / 15) \sum_{q=0}^{\infty}\left(2^{8}\right)^{-q} \leqq 8 / 7,
\end{gathered}
$$

and from (2.6) we get

$$
\left|h^{\prime}(z)\right| \leqq \frac{256 k}{225} \sum_{q=0}^{\infty}\left(2^{8}\right)^{-q} \leqq \frac{115 k}{100} .
$$

From (2.5) and (2.9) we deduce that if $\left|g_{s}(z)\right| \leqq 5 / 2$, then

$$
\varrho\left(f_{k}(z)\right) \leqq\left|g_{s}^{\prime}(z)\right|+\left|h^{\prime}(z)\right| \leqq 8 k(5 / 2)(1+5 / 2)+\frac{115 k}{100}<72 k,
$$

and if $\left|g_{s}(z)\right|>5 / 2$, it follows from (2.5), (2.8) and (2.9) that

$$
\varrho\left(f_{k}(z)\right) \leqq\left|h^{\prime}(z)\right|+\frac{\left|g_{s}^{\prime}(z)\right|}{1+\left(\left|g_{s}(z)\right|-|h(z)|\right)^{2}}
$$

$$
\leqq \frac{115 k}{100}+\frac{\left|g_{s}^{\prime}(z)\right|}{\left|g_{s}(z) / 2\right|^{2}} \leqq \frac{115 k}{100}+32 k\left|\frac{g_{s}(z)-1}{g_{s}(z)}\right| \leqq \frac{115 k}{100}+32 k(1+2 / 5)<72 k .
$$

Combining (2.10), (2.11) and (2.7), we get (2.1). Lemma 1 is proved.

Lemma 2. Let $k \geqq 9$ be an integer, $k \leqq \log A \leqq k+1$, and

Then

$$
f(z)=\prod_{n=1}^{\infty}\left(1-z / A^{n}\right)^{k^{n}}
$$

$$
\limsup _{r \rightarrow \infty} \frac{r \mu(r, f)}{N(r, 0, f)} \leqq 12,
$$

the order of $f$ is $(\log A)^{-1} \log k$,

$$
|z|^{-2}|f(z)| \rightarrow \infty
$$


as $z \rightarrow \infty$ outside the union of the discs $\left|z-A^{n}\right| \leqq A^{n} / 2$,

$$
|z|^{2}|f(z)| \rightarrow 0
$$

as $z \rightarrow \infty$ through the union of the discs $\left|z-A^{n}\right| \leqq A^{n} / 9$, and

$$
N\left(A^{n}, 0, f\right)=(1+o(1)) k^{n+1}(k-1)^{-2} \log A
$$

as $n \rightarrow \infty$.

Proof. We have

$$
N\left(A^{n}, 0, f\right)=\sum_{p=1}^{n-1} k^{p} \log \left(A^{n} / A^{p}\right)
$$

$$
\begin{gathered}
=\sum_{p=1}^{n-1} k^{p} n \log A-\log A \sum_{p=1}^{n-1} p k^{p}=\left(\frac{n\left(k^{n}-k\right)}{k-1}-\frac{k\left(1+(n-1) k^{n}-n k^{n-1}\right)}{(k-1)^{2}}\right) \log A \\
=(1+o(1)) k^{n+1}(k-1)^{-2} \log A \quad(n \rightarrow \infty),
\end{gathered}
$$

which proves (2.15).

For $n \geqq 2$, we write

We have

$$
g_{n}(z)=\prod_{p=1}^{n-1}\left(1-z / A^{p}\right)^{k^{p}} \prod_{p=n+1}^{\infty}\left(1-z / A^{p}\right)^{k^{p}} .
$$

$$
\log \left|g_{n}\left(A^{n}\right)\right| \leqq \log \prod_{p=1}^{n-1}\left(A^{n} / A^{p}\right)^{k^{p}}=N\left(A^{n}, 0, f\right)
$$

and for $\pi / 2 \leqq \varphi \leqq 3 \pi / 2$

$$
\log \left|g_{n}\left(A^{n} e^{i \varphi}\right)\right| \geqq \log \prod_{p=1}^{n-1}\left(A^{n} / A^{p}\right)^{k^{p}}=N\left(A^{n}, 0, f\right) .
$$

Let $A^{n} / 2-1 \leqq|z| \leqq 2 A^{n}$. We get

$$
\left|\frac{g_{n}^{\prime}(z)}{g_{n}(z)}\right|=\left|\sum_{p \neq n} k^{p} /\left(z-A^{p}\right)\right| \leqq\left(|z|-A^{n-1}\right)^{-1} \sum_{p=1}^{n-1} k^{p}+2 \sum_{p=n+1}^{\infty}(k / A)^{p}
$$

$$
\begin{gathered}
\leqq \frac{\left(A^{n} / 2\right) k^{n-1}}{\left(A^{n} / 2-A^{n-1}-1\right)|z|(1-1 / k)}+\frac{2(k / A)^{n+1}}{1-k / A} \leqq \frac{k^{n-1}}{(1-3 / A)|z|(1-1 / k)}+\frac{4 k^{n+1}}{|z| A(1-k / A)} \\
\leqq \frac{k^{n-1}}{|z|}\left(\frac{1}{(1-3 / A)(1-1 / k)}+\frac{4 k^{2}}{A-k}\right) \leqq \frac{7 k^{n-1}}{6|z|} .
\end{gathered}
$$

Let $\left|z-A^{n}\right| \leqq A^{n} / 9$. It follows from (2.17) and (2.19) that

$$
\begin{gathered}
\log \left|g_{n}(z)\right|=\log \left|g_{n}(z) / g_{n}\left(A^{n}\right)\right|+\log \left|g_{n}\left(A^{n}\right)\right| \\
\leqq N\left(A^{n}, 0, f\right)+\left|\int_{z}^{A^{n}}\left(g_{n}^{\prime}(w) / g_{n}(w)\right) d w\right| \\
\leqq N\left(A^{n}, 0, f\right)+\left(A^{n} / 9\right)\left(7 k^{n-1}\right)\left(6(1-1 / 9) A^{n}\right)^{-1} \leqq N\left(A^{n}, 0, f\right)+(7 / 48) k^{n-1},
\end{gathered}
$$


and we deduce from (2.16) and (2.20) that

$$
\begin{gathered}
\log \left|z^{2} f(z)\right| \leqq 3 \log A^{n}-k^{n} \log 9+N\left(A^{n}, 0, f\right)+(7 / 48) k^{n-1} \\
\leqq-k^{n-1}\left((\log A-1) \log 9-k^{2}(k-1)^{-2} \log A\right)+(7 / 48+o(1)) k^{n-1} \\
\leqq-k^{n-1}(6+o(1)) \quad(n \rightarrow \infty) .
\end{gathered}
$$

This proves (2.14).

Let $A^{n} / 2 \leqq|z| \leqq 2 A^{n}, \quad\left|z-A^{n}\right| \geqq A^{n} / 2$ and $\operatorname{Im} z \geqq 0$. Integrating along the positive imaginary axis and the circle $|w|=|z|$, we get from (2.18) and (2.19)

$$
\begin{gathered}
\log \left|g_{n}(z)\right| \geqq \log \left|g_{n}\left(i A^{n}\right)\right|-\left|\int_{A^{n}}^{z}\left(g_{n}^{\prime}(w) / g_{n}(w)\right) d w\right| \\
\geqq N\left(A^{n}, 0, f\right)-\left(7 k^{n-1} / 6\right)\left(\left|\int_{A^{n}}^{|z|} r^{-1} d r\right|+\pi / 2\right) \\
\geqq N\left(A^{n}, 0, f\right)-\left(7 k^{n-1} / 6\right)(\log 2+\pi / 2) \geqq N\left(A^{n}, 0, f\right)-2.643 k^{n-1} .
\end{gathered}
$$

This implies together with (2.16) that

$$
\begin{aligned}
\log \left|z^{-2} f(z)\right| & \geqq N\left(A^{n}, 0, f\right)-2.643 k^{n-1}-k^{n} \log 2-3 \log A^{n} \\
\geqq k^{n-1}(\log A-k \log 2-2.643+o(1)) \geqq k^{n-1}((1-\log 2) \log A-2.643+o(1)) & \geqq(1 / 9+o(1)) k^{n-1} \quad(n \rightarrow \infty) .
\end{aligned}
$$

Since $|f(\bar{z})|=|f(z)|$, we deduce that (2.23) holds for all $z$ satisfying the conditions $A^{n} / 2 \leqq|z| \leqq 2 A^{n}$ and $\left|z-A^{n}\right| \geqq A^{n} / 2$. Using the minimum principle, we get (2.13) from (2.23).

It follows from (2.16) that

$$
\lim _{n \rightarrow \infty} \frac{\log N\left(A^{n}, 0, f\right)}{\log A^{n}}=\frac{\log k}{\log A},
$$

which shows that the order of $f$ is at least $(\log A)^{-1} \log k$.

Let $2 A^{n-1} \leqq r \leqq 2 A^{n}$. It follows from (2.13) that

$$
m\left(2 A^{n}, 0, f\right)=o(1) \quad(n \rightarrow \infty),
$$

and we deduce from the first main theorem of the Nevanlinna theory and (1.16) that

$$
\begin{gathered}
\frac{\log T(r, f)}{\log r} \leqq \frac{(1+o(1)) \log N\left(2 A^{n}, 0, f\right)}{(n-1) \log A} \\
\leqq \frac{(1+o(1)) \log N\left(A^{n+1}, 0, f\right)}{(n-1) \log A} \leqq(\log A)^{-1} \log k+o(1) \quad(n \rightarrow \infty),
\end{gathered}
$$

which shows that the order of $f$ is at most $(\log A)^{-1} \log k$. We have shown that the order of $f$ is $(\log A)^{-1} \log k$. 
Let $h(z)=f(z)$ if $\left|z-A^{n}\right| \leqq A^{n} / 9$ and $h(z)=1 / f(z)$ if $z$ lies outside the union of the discs $\left|z-A^{n}\right|<A^{n} / 2$. It follows from (2.13) and (2.14) that

$$
\varrho(f(z)) \leqq\left|h^{\prime}(z)\right|=\left|(2 \pi i)^{-1} \int_{|z-w|=1} \frac{h(w)}{(w-z)^{2}} d w\right|=O\left(\left|z^{-2}\right|\right)
$$

as $z \rightarrow \infty$ outside the union of the annuli

$$
D_{n}=\left\{z: A^{n} / 9-1<\left|z-A^{n}\right|<1+A^{n} / 2\right\} .
$$

Let $z \in D_{n}$. It follows from (2.19) that

$$
\begin{gathered}
|z| \varrho(f(z)) \leqq|z|\left|f^{\prime}(z) / f(z)\right| \leqq|z|\left|g_{n}^{\prime}(z) / g_{n}(z)\right|+|z| k^{n}\left|z-A^{n}\right|^{-1} \\
\leqq 7 k^{n-1} / 6+k^{n}\left(A^{n}+A^{n} / 9\right)\left(A^{n} / 9-1\right)^{-1} \leqq k^{n-1}(7 / 6+10 k+o(1)) \quad(n \rightarrow \infty) .
\end{gathered}
$$

This implies together with (2.24) that

$$
r \mu(r, f) \leqq k^{n-1}(7 / 6+10 k+o(1)) \quad(n \rightarrow \infty)
$$

for $A^{n} / 2-1<r<2 A^{n}$. For these values of $r$ we get from (2.16)

$$
\begin{aligned}
N(r, 0, f) & \geqq N\left(A^{n} / 2-1,0, f\right) \geqq N\left(A^{n}, 0, f\right)-\frac{k^{n-1}}{1-1 / k} \log \frac{A^{n}}{A^{n} / 2-1} \\
& \geqq k^{n-1}(\log A-(9 / 8) \log 2+o(1)) \quad(n \rightarrow \infty),
\end{aligned}
$$

which together with (2.25) and the fact that $9 \leqq k \leqq \log A$ implies that

$$
\begin{aligned}
& \frac{r \mu(r, f)}{N(r, 0, f)} \leqq \frac{7 / 6+10 \log A}{\log A-(9 / 8) \log 2}+o(1) \\
\leqq & \frac{7 / 6+90}{9-(9 / 8) \log 2}+o(1) \leqq 12+o(1) \quad(n \rightarrow \infty) .
\end{aligned}
$$

This together with (2.24) proves (2.12). Lemma 2 is proved.

Lemma 3. Let $0<d \leqq 1$ and $0<\lambda \leqq(\log 9) / 9$ be given. There exists a meromorphic function $g$ of order $\lambda$ such that $\delta(\infty, g)=d$ and that

$$
\limsup _{r \rightarrow \infty} \frac{r \mu(r, g)}{T(r, g)} \leqq 12 d .
$$

Proof. We choose a positive integer $k \geqq 9$ such that

$$
\frac{\log (k+1)}{k+1} \leqq \lambda \leqq \frac{\log k}{k}
$$

and choose $A>0$ such that $(\log A)^{-1} \log k=\lambda$. It follows from (2.27) that

$$
\log A=\frac{\log k}{\lambda} \geqq k
$$


and that

$$
\log A=\frac{\log k}{\lambda} \leqq \frac{(k+1) \log k}{\log (k+1)}<k+1
$$

We choose $f(z)$ as in Lemma 2 corresponding to these values of $k$ and $A$.

If $d=1$, we set $g=f$, and deduce from Lemma 2 that $g$ is an entire function satisfying the assertions of Lcmma 3 .

Let us suppose that $0<d<1$. We set

$$
b=1 / d-1,
$$

and we denote by $[x]$ the integral part of a positive real number $x$. We set

$$
s_{p}=1+\left[\left(b k^{p} / 8\right)^{1 / 2}\right], \quad h_{p}(z)=f_{s_{p}}\left(8 p A^{-p}\left(z-A^{p}\right)\right),
$$

where $f_{s_{p}}$ is as in Lemma 1 , and

$$
h(z)=\sum_{p=1}^{\infty} h_{p}(z) .
$$

It follows from Lemma 1 that

$$
\varrho\left(h_{p}(z)\right)=8 p A^{-p} \varrho\left(f_{s_{p}}\left(8 p A^{p}\left(z-A^{p}\right)\right) \leqq 576 p s_{p} A^{-p}\right.
$$

for any $z \in C$ and that

$$
\left|h_{p}(z)\right| \leqq\left|\frac{A^{p}}{4 p\left(z-A^{p}\right)}\right|^{6 s_{p}}
$$

if $\left|z-A^{p}\right| \geqq A^{p} /(2 p)$.

Let $n \geqq 9, A^{n} / 2 \leqq|z| \leqq A^{n+1} / 2$ and $\left|z-A^{n}\right| \geqq A^{n} /(2 n)$. It follows from (2.29) and (2.31) that

$$
\begin{gathered}
|z|^{2}\left(\left|h_{n}(z)\right|+\left|h(z)-h_{n}(z)\right|\right) \\
\leqq A^{2 n+2}\left(2^{-6 s_{n}}+\sum_{p=1}^{n-1}\left(A^{p} / A^{n}\right)^{6 s_{p}}+\sum_{p=n+1}^{\infty} \exp \left(-2 s_{p}\right)\right) \\
\leqq A^{2 n+2}\left(\sum_{1 \leqq p \leqq n / 2}\left(A^{-n / 2}\right)^{6}+\sum_{p>n / 2} \exp \left(-2 s_{p}\right)\right) \\
\leqq(1+o(1)) A^{2 n+2}\left(n A^{-3 n}+\sum_{p>n / 2} \exp \left(-k^{p / 3}\right)\right) \\
\leqq(1+o(1)) A^{2 n+2}\left(n A^{-3 n}+\exp \left(-k^{n / 6}\right)\right)=o(1) \quad(n \rightarrow \infty) .
\end{gathered}
$$

This implies that

$$
\left|z^{2} h(z)\right| \rightarrow 0
$$

as $z \rightarrow \infty$ outside the union of the discs $\left|z-A^{n}\right|<A^{n} /(2 n)$, and, together with the 
maximum principle, that

$$
\left|z^{2}\right|\left|h(z)-h_{n}(z)\right| \leqq o(1) \quad(n \rightarrow \infty)
$$

in $\left|z-A^{n}\right| \leqq 3 A^{n} /(4 n)$.

We set $g(z)=f(z)+h(z)$. Let $n>9$ and $\left|z-A^{n}\right| \leqq 3 A^{n} /(4 n)$. We write

$$
g(z)=h_{n}(z)+H_{n}(z) .
$$

It follows from (2.33) and Lemma 2 that

$$
\left|z^{2} H_{n}(z)\right| \leqq o(1) \quad(n \rightarrow \infty)
$$

which implies that

$$
\left|H_{n}^{\prime}(z)\right|=\left|(2 \pi i)^{-1} \int_{|w-z|=1} H_{n}(w)(w-z)^{-2} d w\right| \leqq o\left(\left|z^{-2}\right|\right) \quad(n \rightarrow \infty)
$$

in $\left|z-A^{n}\right| \leqq 5 A^{n} /(8 n)$. Since

$$
\varrho(g(z)) \leqq \frac{\left|h_{n}^{\prime}(z)\right|}{1+\left|h_{n}(z)+H_{n}(z)\right|^{2}}+\left|H_{n}^{\prime}(z)\right|,
$$

we get from (2.29), (2.30), (2.34), (2.35) and Lemma 2

(2.36) $|z| \varrho(g(z)) \leqq(576+o(1)) n s_{n} A^{-n}|z| \leqq(576+o(1)) n s_{n}=o\left(s_{n}^{2}\right)=o\left(k^{n}\right)$

in $\left|z-A^{n}\right| \leqq 5 A^{n} /(8 n)$.

$$
=o(N(|z|, 0, f)) \quad(n \rightarrow \infty)
$$

As in the connection of (2.35), we deduce from (2.32) that

$$
\left|h^{\prime}(z)\right|=o\left(|z|^{-2}\right)
$$

as $z \rightarrow \infty$ outside the union of the discs $\left|z-A^{n}\right|<5 A^{n} /(8 n)$. Since

$$
\varrho(g(z)) \leqq \frac{\left|f^{\prime}(z)\right|}{1+\mid f(z)+h(z)^{2}}+\left|h^{\prime}(z)\right|,
$$

it follows from Lemma 2, (2.32) and (2.37) that

$$
|z| \varrho(g(z)) \leqq(12+o(1)) N(|z|, 0, f)
$$

as $z \rightarrow \infty$ outside the union of the discs $\left|z-A^{n}\right|<5 A^{n} /(8 n)$. This together with (2.36) implies that

$$
r \mu(r, g) \leqq(12+o(1)) N(r, 0, f) \quad(r \rightarrow \infty) .
$$

It follows from (2.29) that

$$
n(r, \infty, g)=(b+o(1)) n(r, 0, f)
$$

as $r \rightarrow \infty$ outside the union of the intervals $\left[A^{n}(1-1 /(2 n)), A^{n}(1+1 /(2 n))\right]$. Let 
$A^{n} \leqq r \leqq A^{n+1}$. It follows from (2.39) that

$$
\begin{aligned}
& |N(r, \infty, g)-b N(r, 0, f)|=\left|\int_{0}^{r}(n(t, \infty, g)-b n(t, 0, f)) t^{-1} d t\right| \\
\leqq & o(N(r, 0, f))+\sum_{p=1}^{n+1} \int_{A^{p}(1-1 /(2 p))}^{A^{p}(1+1 /(2 p))}|n(t, \infty, g)-b n(t, 0, f)| t^{-1} d t \\
\leqq & o(N(r, 0, f))+O\left(\sum_{p=1}^{n+1} k^{p} \log \frac{1+1 /(2 p)}{1-1 /(2 p)}\right) \\
\leqq & o(N(r, 0, f))+O\left(\sum_{p=1}^{n+1} k^{p} / p\right) \leqq o(N(r, 0, f))+o\left(k^{n+1}\right) \quad(n \rightarrow \infty),
\end{aligned}
$$

which together with Lemma 2 implies that

$$
N(r, \infty, g)=(b+o(1)) N(r, 0, f) \quad(r \rightarrow \infty) .
$$

Let $A^{p}(1-1 / p) \leqq r \leqq A^{p}(1+1 / p)$. From the first main theorem and (2.32) it follows that

$$
\begin{gathered}
m(r, \infty, h)=T(r, h)-N(r, \infty, h) \leqq T\left(A^{p}(1+1 / p), h\right)-N\left(A^{p}(1-1 / p), \infty, h\right) \\
\leqq N\left(A^{p}(1+1 / p), h\right)-N\left(A^{p}(1-1 / p), h\right)+o(1),
\end{gathered}
$$

and since $N(t, h)=N(t, g)$ for all $t>0$, we deduce from (2.40) and Lemma 2 that

$$
\begin{aligned}
& m(r, h) \leqq(b+o(1)) N\left(A^{p}(1+1 / p), 0, f\right)-b N\left(A^{p}(1-1 / p), 0, f\right) \\
& \leqq O\left(k^{p} \log \frac{1+1 / p}{1-1 / p}\right)+o\left(N\left(A^{p}, 0, f\right)\right) \leqq o(T(r, g)) \quad(p \rightarrow \infty) .
\end{aligned}
$$

This together with (2.32) implies that

$$
m(r, \infty, h)=o(T(r, g)) \quad(r \rightarrow \infty) .
$$

Since

and

$$
m(r, g) \leqq m(r, f)+m(r, h)+\log 2
$$

$$
m(r, f) \leqq m(r, g)+m(r, h)+\log 2,
$$

we deduce from (2.41) that

$$
m(r, g)=(1+o(1)) m(r, f)=(1+o(1)) T(r, f) \quad(r \rightarrow \infty) .
$$

From (2.40) and (2.42) it follows that the functions $f$ and $g$ have the same order, so it follows from Lemma 2 that the order of $g$ is $(\log A)^{-1} \log k=\lambda$.

From (2.40), (2.42) and Lemma 2 we get

$$
\begin{gathered}
\frac{m\left(4 A^{n}, \infty, g\right)}{T\left(4 A^{n}, g\right)}=\frac{T\left(4 A^{n}, f\right)}{T\left(4 A^{n}, f\right)+b N\left(4 A^{n}, 0, f\right)}+o(1) \\
=(1+b)^{-1}+o(1)=d+o(1) \quad(n \rightarrow \infty),
\end{gathered}
$$


which implies that $\delta(\infty, g) \leqq d$. From (2.40) and (2.42) we deduce that

$$
\begin{gathered}
\frac{m(r, \infty, g)}{T(r, g)}=\frac{T(r, f)}{T(r, f)+b N(r, 0, f)}+o(1) \geqq \frac{T(r, f)}{T(r, f)+b T(r, f)}+o(1) \\
=d+o(1) \quad(r \rightarrow \infty),
\end{gathered}
$$

which implies that $\delta(\infty, g) \geqq d$, and we get $\delta(\infty, g)=d$.

From (2.38), (2.40) and (2.42) it follows that

$$
\begin{gathered}
\frac{r \mu(r, g)}{T(r, g)} \leqq \frac{12 N(r, 0, f)}{T(r, f)+b N(r, 0, f)}+o(1) \leqq \frac{12 N(r, 0, f)}{N(r, 0, f)+b N(r, 0, f)}+o(1) \\
=12 d+o(1) \quad(r \rightarrow \infty) .
\end{gathered}
$$

This completes the proof of Lemma 3 .

\section{Proof of Theorem 1}

Let $d$ and $t$ be as in Theorem 1. If $0<t \leqq(\log 9) / 9$, then the function $g$ of Lemma 3 satisfies the assertions of Theorem 1.

Let us suppose that $t>(\log 9) / 9$. We choose a positive integer $k$ such that

$$
k-1<\frac{9 t}{\log 9} \leqq k,
$$

$\lambda=t / k$, and $f(z)=g\left(z^{k}\right)$, where $g$ is the function of Lemma 3 corresponding to these values of $d$ and $\lambda$.

Since

$$
m(r, f)=m\left(r^{k}, g\right)
$$

$$
N(r, f)=N\left(r^{k}, g\right)
$$

for all $r>0$, we deduce from Lemma 3 that $\delta(\infty, f)=\delta(\infty, g)=d$ and that the order of $f$ is $k \lambda=t$.

Since

$$
|z| \varrho(f(z))=k|z|^{k} \varrho\left(g\left(z^{k}\right)\right)
$$

for all $z \in C$, we get from (3.2), (3.3) and Lemma 3

$$
\frac{r \mu(r, f)}{T(r, f)}=\frac{k r^{k} \mu\left(r^{k}, g\right)}{T\left(r^{k}, g\right)} \leqq 12 k d+o(1) \quad(r \rightarrow \infty) .
$$

Since $1 / 5<(\log 9) / 9<1$, we get from $(3.1)$

$$
k \leqq 5((k \log 9) / 9+1-(\log 9) / 9)=5(1+(k-1)(\log 9) / 9)<5(1+t),
$$

which together with (3.4) proves (1.1). Theorem 1 is proved. 


\section{References}

[1] Anderson, J. M., and J. Clunie: Slowly growing meromorphic functions. - Comment. Math. Helv. 40, 1966, 267-280.

[2] Anderson, J. M., and S. Toppila: The growth of the spherical derivative of a meromorphic function of finite lower order. - J. London Math. Soc. (2) 27, 1983, 289-305.

[3] Clunie, J., and W. K. Hayman: The spherical derivative of integral and meromorphic functions. - Comment. Math. Helv. 49, 1966, 117-148.

[4] LeHto, O.: The spherical derivative of meromorphic functions in the neighbourhood of an isolated singularity. - Comment. Math. Helv. 33, 1959, 196-205.

[5] Lehto, O., and K. I. Virtanen: On the behaviour of meromorphic functions in the neighbourhood of an isolated singularity. - Ann. Acad. Sci. Fenn. Ser. A I Math. 240, 1957, 1-9.

[6] Nevanlinna, R.: Analytic functions. - Springer-Verlag, New York-Berlin-Heidelberg, 1970.

[7] Pommerenke, Ch.: Normal functions. - Proceedings of the NRL Conference on Classical Function Theory, Math. Res. Center, Naval Res. Lab., Washington, D. C., 1970, $77-93$.

[8] Toppila, S.: On the growth of the spherical derivative of a meromorphic function. - Ann. Acad. Sci. Fenn. Ser. A I Math. 7, 1982, 119-139.

[9] Toppila, S.: On the spherical derivative of a meromorphic function with a deficient value. Proceedings of the fifth Romanian-Finnish Seminar on Complex Analysis (to appear).

[10] Toppila, S., and J. WinkLeR: On the spherical derivative of a meromorphic function with a Valiron deficient value. - Math. Z. 180, 1982, 545-551.

[11] Toppila, S., and J. Winkler: Some lower bounds for the maximal growth of the spherical derivative. - Complex variables: Theory and application 2, 1983, 1-25.

University of Helsinki

Department of Mathematics

SF-00100 Helsinki 10

Finland

Received 1 February 1983 